\title{
FLORA DE GRÃO-MOGOL, MINAS GERAIS: VERBENACEAE ${ }^{1}$
}

\author{
FÁTIMA REGINA G. SALIMENA* \& TÂNIA REGINA SANTOS SILVA** \\ *Departamento de Botânica - ICB, Universidade Federal de Juiz de Fora, \\ Campus UFJF, 33033-330 - Juiz de Fora, MG, Brasil. \\ **Departamento de Ciências Biológicas, Universidade Estadual de Feira de Santana, km 3 BR 116, \\ Campus Universitário, 44031-460 - Feira de Santana, BA, Brasil.
}

ATKINS, S. 2005. The genus Stachytarpheta (Verbenaceae) in Brazil. Kew Bull. 60(2): 161-272.

BRIQUET, J.I.. Verbenaceae. In H.G.A. Engler \& K.A.E. Prantl (eds.) Die natürlichen Pflanzenfamilien. Wilhelm Engelmann. Leipzig, Teil 4, 3A, p. 132-182.

FRANÇA, F. 2003. Revisão de Aegiphila Jacq. (Lamiaceae) e seu posicionamento sistemático. Tese de Doutorado. Universidade de São Paulo, São Paulo.

SALIMENA, F.R.G. 2000. Revisão taxonômica de Lippia L. sect. Rhodolippia Schauer (Verbenaceae). Tese de Doutorado. Universidade de São Paulo. São Paulo.

SCHAUER, J.C.. Verbenaceae. In A.L.P.P. de Candolle (ed.) Prodromus systematis naturalis regni vegetabilis. Victoris Masson. Paris, vol. 11, p. 522-700.

SILVA, T.R. S. 1999. Redelimitação e revisão taxonômica do gênero Lantana L. (Verbenaceae) no Brasil. Tese de Doutorado. Universidade de São Paulo. São Paulo.

TRONCOSO, N.S.. Los géneros de Verbenáceas de Sudamérica extratropical. Darwiniana 18(3-4): 295-412.

1. Inflorescências em cimeiras

2. Folhas simples; flores actinomorfas, estames isodínamos

Aegiphila lhotzkiana

2'. Folhas compostas, digitadas, flores zigomorfas, estames didínamos Vitex polygama

1 '. Inflorescências em racemos

3. Estames 4, didínamos

4. Fruto drupa Lantana caatingensis

4'. Fruto esquizocarpo .. Lippia

5. Espigas tetrásticas, 4-6 por axila, brácteas verdes, plicado-carenadas, conatas na base ....................... L. gracilis

5'. Espigas polísticas, solitárias ou geminadas, em racemos ou corimbos terminais, brácteas verdes ou róseas, planas, livres

6. Brácteas imbricadas, membranáceas, róseas ou vináceas

7. Espigas hemisféricas, brácteas vináceas, não encobrindo a corola, folhas suborbiculares, ca. $1 \mathrm{~cm}$ compr.

7'. Espigas esféricas ou cilíndricas, brácteas róseas, encobrindo a corola

8. Folhas cordadas, base amplexicaule

L. gardneriana

8'. Folhas ovais, base obtusa

L. hederaefolia

6'. Brácteas laxamente dispostas, verdes

9. Folhas $0,3-1,5 \mathrm{~cm}$ compr.

10. Folhas obovado-cuneadas, 1-1,5cm compr., ápice truncado-retuso, 3-crenado, reticulado-venosa

L. hermannioides

10'. Folhas oblongo-cuneadas, 3-4 mm compr., ápice obtuso, uninérvea L. thymoides

9'. Folhas $2-7,5 \mathrm{~cm}$ compr.

11. Folhas orbiculares, ternadas, corimbos terminais simples

L. rotundifolia

\footnotetext{
${ }^{1}$ Trabalho realizado conforme o planejamento apresentado por Pirani et al. 2003. Bol. Bot. Univ. São Paulo 21(1): 1-24.
} 
11'. Folhas oval-elípticas, rômbico-ovais a oblongas, opostas, panículas corimbosas ou espigas 12. Inflorescências panículas corimbosas, pedúnculos ca. $12 \mathrm{~cm}$ compr. L. lacunosa 12'. Inflorescências espigas capituliformes, pedúnculos 4-9 cm compr

$3^{\prime}$. Estames 2 perfeitos, 2 estaminódios L. spiraeastrum

13. Folhas espatuladas, $0,8-1 \mathrm{~cm}$ compr., espigas $5-10 \mathrm{~cm}$ compr. Stachytarpheta 13'. Folhas oblongo-obovadas ou elíptico-lanceoladas, espigas 3-5 cm compr.

14. Folhas oblongo-obovadas, 5-9 cm compr. S. spathulata 14 '. Folhas elíptico-lanceoladas, 2-4,5 cm compr. S. martiana S. glabra

Nota - No conceito moderno da família Labiatae [Harley et al. 2004. Labiatae In J.W. Kadereit (ed.) The families and genera of vascular plants. (K. Kubitzki, ed.). Springer Verlag. Berlin, vol. 6, p. 167-275], baseado em caracteres macro e micromorfológicos, químicos e moleculares, uma parte significativa da família Verbenaceae foi transferida para esta família. Os gêneros Aegiphila e Vitex, atualmente incluídos entre as Labiatae, foram, entretanto, ainda tratados entre as Verbenaceae na Flora de Grão-Mogol.

\section{Aegiphila Jacq.}

Árvores ou arbustos, dióicos. Inflorescências em cimeiras terminais ou axilares; cálice tubuloso ou ciatiforme, 4-5-denteado; corola hipocraterimorfa, 4-5-lobada; flores estaminadas com 4-5 estames exsertos e pistilódio incluso; flores pistiladas com estaminódios inclusos, ovário 4-locular, estilete exserto e estigma bífido. Fruto drupa monopirenada.

\subsection{Aegiphila lhotzkiana Cham., Linnaea 7: 112. 1832.}

Árvores até $4 \mathrm{~m}$ alt. Folhas cartáceas a coriáceas, oblongo-elípticas, subsésseis, 2,5-6 cm compr., 1,5-4 cm larg., face adaxial lanuginosa glabrescente, face abaxial lanuginoso-tomentosa. Inflorescências em cimeiras solitárias; flores estaminadas com cálice 5-6 mm compr., corola alva, ca. 1 $\mathrm{cm}$ compr., estames ca. $8 \mathrm{~mm}$ compr., pistilódio com ovário estéril, estilete 2-3 mm compr., ramos do estigma 1,5-2 mm compr.; flores pistiladas com cálice 3-4 $\mathrm{mm}$ compr., corola ca. $6 \mathrm{~mm}$ compr., anteras estéreis, ovário ca. 1,5 mm compr., estilete ca. $5 \mathrm{~mm}$ compr., ramos do estigma ca. $3 \mathrm{~mm}$ compr. Drupa oval-elíptica, ca. $8 \mathrm{~mm}$ compr., amarela passando a castanho-avermelhada na maturidade. (Fig. 1. A-C)

Assis et al. CFCR 11470 (SPF); Freire-Fierro et al. CFCR 12604 (SPF).

Desde o Maranhão, Bahia, Goiás, Minas Gerais, Mato Grosso do Sul até São Paulo, florescendo de outubro a março e com queda foliar de junho a agosto. Em Grão-Mogol, ocorre em cerrado e campo rupestre de solo arenoso-cascalhento.

\section{Lantana L.}

Subarbustos ou arbustos, armados ou não. Folhas opostas, ternadas ou verticiladas. Inflorescências elementares em espigas capituliformes geralmente axilares; brácteas verdes; cálice membranáceo, truncado; corola, hipocraterimorfa, limbo 5-lobado; estames 4, didínamos, inclusos, tecas paralelas; ovário 2-carpelar, 1-carpelar por aborto, 2-locular, estilete incluso, estigma decurrente, oblíquo ou sublateral. Fruto drupa.

\subsection{Lantana caatingensis Moldenke, Phytologia 24(4): 298.} 1972.

Arbustos 0,3-2,5 m alt., ramificados, ramos sulcados. Folhas opostas, pecíolo $0,5-1,5 \mathrm{~cm}$ compr., lâmina $1-5 \mathrm{~cm}$ compr., 0,7-3,5 cm larg., dicolaor, oval, base subtruncada a truncada, margem crenada, ápice obtuso, face abaxial tomentosa, tricomas simples, alvos, face adaxial minuto-hirtela, tricomas simples, alvos. Inflorescências axilares, pedúnculo $1-2 \mathrm{~cm}$ compr., espigas captuliformes hemisféricas, $0,5-1 \mathrm{~cm}$ compr., brácteas 2 basais largo-ovais, 5-8 x ca. $4 \mathrm{~mm}$, ápice agudo, as internas oblongas 4-5 x ca. 2 mm, ápice agudo a acuminado, membranáceas, minuto-tomentosas a glabrescentes; cálice ca. $1 \mathrm{~mm}$ compr, 2-lobado, ápice truncado, minuto-tomentoso; corola alva, rósea ou lilás, fauce amarela, tubo 5-6,5 mm compr. puberulento. Fruto ovóide, vináceo, superfície estriada, mesocarpo suculento e conspícuo. (Fig. 1. S-U)

\section{Pirani et al. CFCR 8465 (CESJ, SPF).}

Pernambuco, Bahia e Minas Gerais, em campos rupestres, cerrados, caatinga e em matas de altitude. Em Grão- 
Mogol, foi encontrada com flor e fruto em setembro, em campo rupestre de morro próximo ao Rio Itacambiruçu.

Cadeia do Espinhaço de Minas Gerais, em afloramentos quartzíticos, em solo arenoso de campos rupestres, carras- cal ou cerrados. Em Grão-Mogol, é muito freqüente nos carrascais e beiras de córregos doVale do Rio Itacambiruçu, ocorrendo também nas vargens do alto da serra (campos de cimeira). Floresce praticamente ao longo do ano todo.

\section{Lippia L.}

Arbustos ou subarbustos. Inflorescências racemosas em corimbos, racemos, espigas, capítulos ou tirsos. Brácteas coloridas ou não, plicadas, côncavas ou planas. Cálice membranáceo, 2-labiado, 2-4-dentado; corola hipocraterimorfa ou infundibuliforme, zigomorfa, limbo 2-labiado, lábio anterior 3-lobado. Estames 4, didínamos, inclusos.Ovário 2-locular, lóculos 1-seminado. Fruto esquizocarpo.

\subsection{Lippia bradei Moldenke, Phytologia 3 (2): 61-62. 1949.}

Arbustos 0,5-1,5 m alt., odoríferos, ramos tetragonais, densamente glandulosos; internós 1-2 cm compr. Folhas opostas, pecíolos ca. $3 \mathrm{~mm}$ compr., coriáceas, suborbiculares, 6-10 cm compr., 5-12 cm larg., margem subrevoluta, densamente glandulosa em ambas as faces, glabrescentes. Inflorescências axilares, 2 por nó, pedúnculos $1-1,5 \mathrm{~cm}$ compr., alongando-se até $4 \mathrm{~cm}$ na frutificação; brácteas verde-vináceas, base vinácea ou rosadas, elípticas, ca. $5 \mathrm{~mm}$ compr., ca.1,5 mm larg., densamente glandulosa, ápice subagudo; cálice verde-claro, membranáceo, inconspícuo; corola lilás, rosa magenta ou rosa-claro, fauce e interior do tubo alvos, tubo ca. $4 \mathrm{~mm}$, limbo ca. $3 \mathrm{~mm}$ diâm., densamente glandulosa externamente. (Fig. 1. L-M)

Cordeiro \& Mello-Silva CFCR 10029 (BHCB, CESJ, MBM, NY, SPF); Mello-Silva \& Pirani CFCR 10781 (CESJ, SP, SPF); Mello-Silva et al. CFCR 8499 (CESJ, SPF); Sano et al. CFCR 12474 (CESJ, R, $\mathrm{SPF})$; Zappi et al. CFCR 13147 (SPF).

Região norte da Cadeia do Espinhaço de Minas Gerais, em campos rupestres. Em Grão-Mogol, ocorre entre rochas ou solo arenoso, nos campos rupestres, e encostas esacrposas. Foi coletada com flores em maio, setembro e dezembro.

\subsection{Lippia gardneriana Schauer in A.DC., Prodr. 11: 592.} 1847.

Subarbustos, ca. $60 \mathrm{~cm}$ alt., ramos hirsutos, glandulosos. Folhas opostas, decussadas, sésseis, oval-cordadas, 1,0-2,3 cm compr., 1,3-2,5 cm larg., base cordada, amplexicaule, margem dentada a grosseiramente serreada, revoluta, ápice agudo, face adaxial bulada, hirsuta, face abaxial com nervuras proeminentes, tricomas glandulares alvos, densamente hirsuta ao longo das nervuras. Inflorescências axilares, pedúnculos 2,5-7,5 cm compr., glanduloso, espigas capituliformes, globosas, $2-3 \mathrm{~cm}$ diâm.; brácteas membranáceas, róseas, oval-cordadas, ca. 1,2 cm compr., ca. 1,5 $\mathrm{cm}$ larg., ápice agudo, base amplexicante, glandulosas em ambas as faces; cálice ca. $2 \mathrm{~mm}$ compr., hirsuto, 2-dentado, dentes curtos; corola rosa, tubo ca. $8 \mathrm{~mm}$ compr., ventricoso. (Fig. 1. Q-R)

\section{Simão-Bianchini et al. CFCR 13162 (SPF).}

Ocorre em áreas restritas de cerrado em Goiás e Norte de Minas Gerais. Em Grão-Mogol, ocorre na transição cerradocampo rupestre.

\subsection{Lippia gracilis Schauer in A.DC., Prodr. 11: 576. 1847.}

Arbustos, 1-2 $\mathrm{m}$ alt., ramificados, aromáticos. Folhas ovais a oblongo-ovais, 0,6-1,6 cm compr. 0,3-1,5 cm larg., ápice obtuso, margem crenada, base obtusa, discolores, face adaxial bulada, reticulada, velutina, glandulosa, rufescente, face adaxial conspicuamente reticulado-venosa, velutina. Inflorescências axilares 2-4, tetrásticas, brácteas membranáceas, ovais, imbricadas, conatas na base, glandulosas; corola alva, $0,5-1,8 \mathrm{~cm}$ compr. (Fig. 1. I-K)

Freire-Fierro et al. CFCR 12374 (BHCB, CESJ, F, SPF); Mamede et al. CFCR 3516 (CESJ, SPF); Pirani et al. CFCR 11345 (BHCB, CESJ, SPF, U, UB); Sano et al. CFCR 12456 (CESJ, K, MBM, SPF); Silva et al. CFCR 12690 (CESJ, SPF).

Desde a Amazônia e Pará até Minas Gerais e São Paulo, em áreas de cerrado ou campos rupestres. Em Grão-Mogol, ocorre em campo sujo, carrascos e cerrados. Foi coletada com flores em maio novembro e dezembro.

\subsection{Lippia hederaefolia Mart. \& Schauer ex Schauer in} A.DC., Prodr. 11: 593. 1847.

Subarbustos 0,5-1 m alt., sistema subterrâneo desenvolvido, ramos tetragonais, escabros, angulosos. Folhas subsésseis, concentradas no ápice dos ramos, opostas, ovais, 0,5-1 cm compr., 0,4-1 cm larg., base subcuneada, margem denteada-lobada, subrevoluta, ápice agudo, face adaxial estrigosoescabra, face abaxial glandulosa, pulverulenta. Inflorescências axilares em corimbos, ca. 1,5-2 cm diâm., pedúnculos ca $2,5 \mathrm{~cm}$ compr., filiformes; brácteas petalóides, involucrais, róseas, lilás ou vináceas, ovais, $0,8-1,2 \mathrm{~cm}$ compr., ápice 

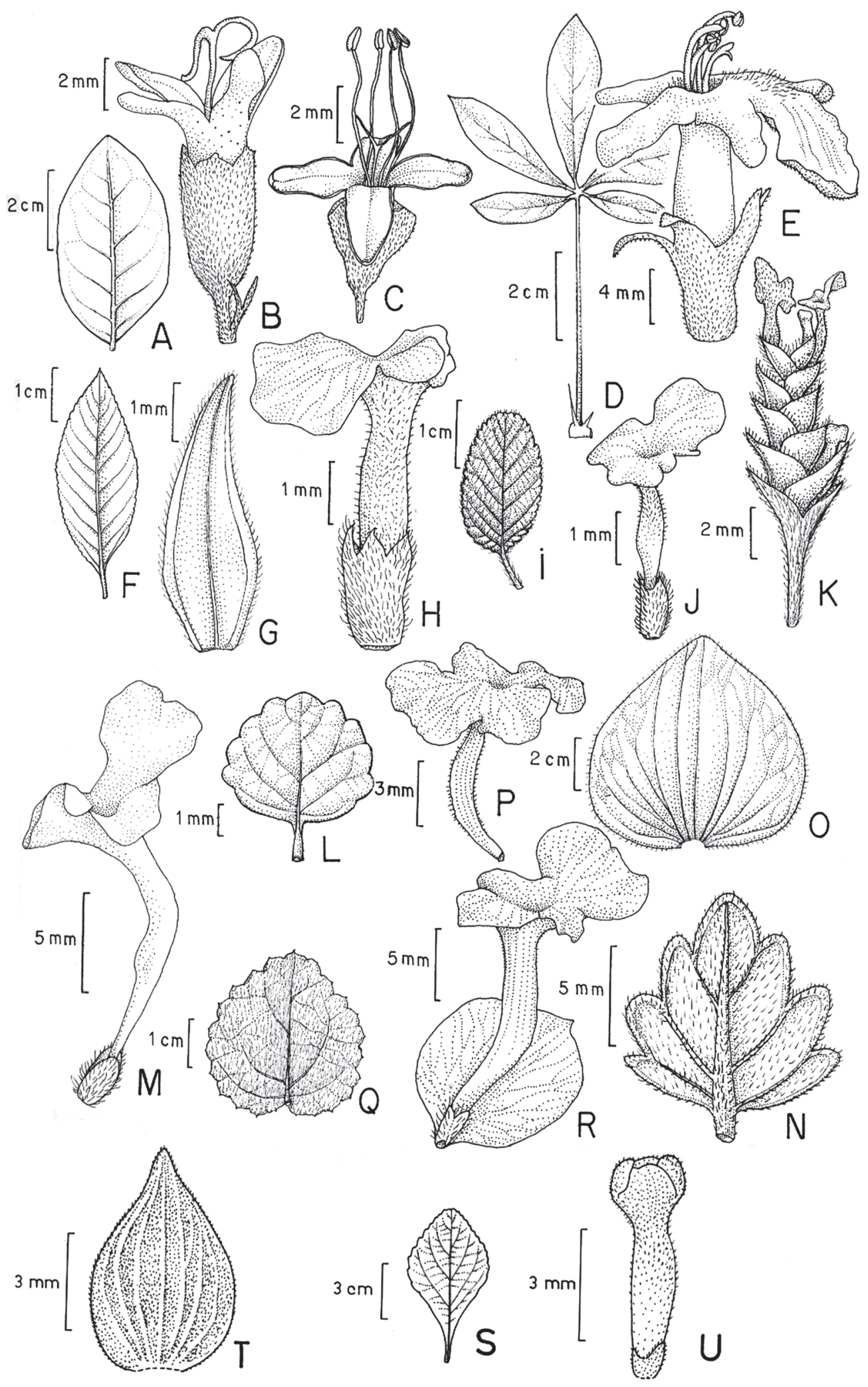

Fig. 1. VERBENACEAE. A-D. Aegiphila lhotzkiana: A. Folha; B. Flor pistilada; C. Flor estaminada. D-E. Vitex polygama: D. Folha; E. Flor, vista lateral. F-H. Lippia spiraeastrum: F. Folha; G. Bráctea; H. Flor, vista lateral. I-K. Lippia gracilis: I. Folha; J. Flor, vista frontal; K. Inflorescência. L-M. L. bradei. L. Folha; M. Flor, vista lateral. N-P. L. hederaefolia: N. Folha;O. Bráctea; P. Flor, vista lateral. Q-R. L. gardneriana: Q. Folha; R. Bráctea e flor. S-U. Lantana caatingensis: S. Folha; T. Brácteas; U. Botão floral. 
agudo ou obtuso, 5-7-nérveas, reticulada, ciliada; cálice ca. ca. $3 \mathrm{~mm}$ compr., híspido, bífido, lobos agudos bidentados; corola rosa ou violeta, pilosa externamente, tubo ca. $6 \mathrm{~mm}$ compr., lobo superior emarginado, laterais oval-obtusos, lobo inferior obovado. (Fig. 1. N-P)

Campos et al. CFCR 13344 (CESJ, MBM, SPF); Furlan et al. CFCR 692 (SPF); Mello-Silva et al. CFCR 10149 (BHCB, CESJ, K, NY, SPF); Silva et al. CFCR 12729 (SPF).

Minas Gerais e Bahia, em áreas abertas pedregosas. Em Grão-Mogol, ocorre em campo-cerrado e carrascal, em solo arenoso-pedregoso, florescendo nos meses de abril a julho, e de setembro a dezembro.

\subsection{Lippia hermannioides Cham., Linnaea 7: 219. 1832.}

Arbustos aromáticos, 1-2 m alt. Folhas decussadas, elípticas, obovadas a suborbiculares, $1-2 \mathrm{~cm}$ compr., $0,5-1 \mathrm{~cm}$ larg., face adaxial escabra, face abaxial hirtela, glanduloso-estrigosa. Inflorescências em espigas 1-1,5 cm compr., 3-5-floras, brácteas verdes, lanceoladas, 0,6-1 cm compr., 2-3 mm larg.; cálice campanulado ca. $5 \mathrm{~mm}$ compr., ca. 1,5 $\mathrm{mm}$ larg.; corola hipocraterimorfa, alva a rosa, até lilás, fauce e interior do tubo amarelos. Fruto obcônico apiculado, ca. $2 \mathrm{~mm}$ compr., testa lisa. (Fig. 2. A-B)

\section{Cordeiro et al. CFCR 997(CESJ, K, SPF).}

Goiás, Minas Gerais e Rio de Janeiro (Itatiaia), em populações densas na orla das matas ciliares ou nos campos arenosos e pedregosos. Apresenta floração ao longo de todo o ano, com flores fortemente aromáticas. Em Grão-Mogol, só foi encontrada próximo ao Rio Ventania.

\subsection{Lippia lacunosa Mart. \& Schauer in Mart., Fl. Bras. 246.} 1851 .

Arbustos 1,2-1,8 m alt., ramos hirsutos-escabros. Folhas opostas, decussadas, ovais, coriáceas, ápice obtuso, margem crenada, base cordada, face adaxial nítida, escabra, face abaxial foveolada, tomentosa. Inflorescências axilares, em corimbos, pedúnculos ca. $1 \mathrm{~cm}$, espigas cilíndricas, ca. 1,3 cm compr., ca. $1 \mathrm{~cm}$ larg., brácteas verdes, cartáceas, ovallanceoladas, ca. $3 \mathrm{~mm}$ compr., densamente glandulosa, ápice acuminado; cálice ca. $2 \mathrm{~mm}$ compr., viloso-hirsuto externamente, bilobado; corola lilás, fauce amarela, tubo ca. $6 \mathrm{~mm}$, ventricoso, externamente glanduloso, limbo oblíquo, lobo superior truncado, lobos laterais ovais, lobo inferior elíptico, truncado. (Fig. 2. I-K)

Mello-Silva et al. 1431 (BHCB, K, SPF); Simão-Bianchini et al. CFCR 12842 (CESJ, CTES, MBM, SPF, U).

Minas Gerais, em campos rupestres, formando população com numerosos indivíduos em solo arenoso de áreas de tran- sição cerrado-campo sujo. Muito próxima de L rotundifolia da qual difere principalmente pela morfologia das folhas, ovais em L. lacunosa e orbiculares em L. rotundifolia. Em Grão-Mogol, foi colhida com flores em junho e setembro.

\subsection{Lippia rotundifolia Cham., Linnaea 7: 230. 1832.}

Arbustos 0,5-2 m alt., sistema subterrâneo desenvolvido. Folhas ternadas, coriáceas, 2-4 cm compr., 1,5-3 cm larg., orbiculares a ovais, ápice obtuso, margem crenada, base obtusa a cuneada, face adaxial nítida, escabra, face abaxial tomentosa, areolada. Inflorescências espiciformes, em corimbos, pedúnculos 0,5-2 cm compr.; brácteas lanceoladas, curvas 0,7-1 cm compr., 5-nérveas, hirsutas; cálice membranáceo hirsuto-glanduloso, ca. 2 mm compr., 2-partido, 2-dentado; corola lilás ou magenta, fauce amarela, tubo cilíndrico, ventricoso, ca. $1 \mathrm{~cm}$ compr., limbo 4-lobado, lobos obovadostruncados; ovário obcônico ca. $1 \mathrm{~mm}$, estilete ca. $2 \mathrm{~mm}$ compr. Fruto ca. $2 \mathrm{~mm}$ diâm., castanho, mericarpos com face comissural papilosa e face convexa lisa. (Fig. 2. F-H)

\section{Giulietti et al. CFCR 9911 (SPF).}

Goiás, Distrito Federal e Minas Gerais, em campos rupestres. Em Grão Mogol, é arbusto heliófilo, encontrado entre rochas, em solo arenoso com floração durante todo o ano.

3.8. Lippia spiraeastrum (Mart. \& Schauer ex Schauer) T. Silva, Darwiniana 40(1-4): 57-59. 2002.

Arbustos 1,5-2,5m alt., viscoso, ramos sulcados. Folhas opostas, pecíolo ca. $7 \mathrm{~mm}$, lâmina 3,5-7,5 cm compr., 2-4 cm larg., discolor, rômbeo-oval a oblongo-aguda, base triangular-cuneada, margem serrilhado-crenulada, ápice agudo, face adaxial glandulosa, tricomas glandulares sésseis, face abaxial tomentosa. Inflorescências axilares, pedúnculos 4-9 $\mathrm{cm}$ compr., espigas capituliformes hemisféricas, ca. $7 \mathrm{~mm}$ compr., ca. 1,2 cm larg., brácteas ovais, ápice acuminado, ca. $3 \mathrm{~mm}$ compr., coriáceas, ciliada, escabras, cálice ca. $2 \mathrm{~mm}$ compr., bilobado, hirsuto; corola lilás ou rosa, tubo amarelo, ca. $8 \mathrm{~mm}$ compr., externamente hirsuto. Fruto obovado, negro, superfície lisa, mesocarpo seco, ca. $2 \mathrm{~mm}$ compr. (Fig. 1. F-H)

Cordeiro et al. CFCR 929 (SPF); Mamede et al. CFCR 3513 (SPF); Oliveira et al. CFCR 12937 (NY, SPF); Pirani et al. CFCR 8530 (BHCB, CESJ, K, MBM, SPF); Silva et al. CFCR 12597 (CESJ, SPF), CFCR 12603 (CESJ, K, RB, SPF); Zappi et al. CFCR 12083 (CESJ, CTES, SPF).

Cadeia do Espinhaço de Minas Gerais, em afloramentos quartzíticos, em solo arenoso de campos rupestres, carrascal ou cerrados. Em Grão-Mogol, é muito freqüente nos carrascais e beiras de córregos do vale do Rio Itacambiruçu, ocorrendo também nas vargens do alto da serra (campos de cimeira). Floresce praticamente ao longo do ano todo. 
3.9. Lippia thymoides Mart. \& Schauer ex Schauer in A.DC., Prodr. : 586. 1847.

Arbustos ca. $1 \mathrm{~m}$ alt., ramos virgatos com braquiblastos, escabros. Folhas opostas nos ramos normais, fasciculadas nos braquiblastos, discolores, coriáceas, $0,5-1 \mathrm{~cm}$ compr., 2-3 mm larg., oblongo-cuneadas, ápice obtuso, mucronado, margem inteira, revoluta, face adaxial escabra, uninérvea, face abaxial glandular-pulverulenta. Inflorescências axilares, solitárias, subglobosas, compactas, ca. $1 \mathrm{~cm}$ compr.; brácteas imbricadas, oval-lanceoladas, ápice agudo, 3-nérvea, glandulosa, ciliada; cálice ca. $2 \mathrm{~mm}$ compr., bilobado; corola rósea, fauce alva, infundibuliforme, ca. $7 \mathrm{~mm}$ compr. (Fig. 2. C-E)

Taylor et al. 1054 (K, SPF).

Região norte da Cadeia do Espinhaço de Minas Gerais e Bahia, em áreas de cerrado e campos rupestres, formando grandes populações. Em Grão-Mogol, ocorre entre rochas no campo rupestre e floresce em janeiro.

\section{Stachytarpheta Vahl}

Ervas ou arbustos. Folhas opostas ou alternas. Inflorescências terminais em espigas. Flores sésseis freqüentemente imersas na ráquis carnosa; brácteas adpressas.; cálice tubuloso, 5-costado, 5-dentado, persistente no fruto; corola azul, lilás ou roxa, tubo cilíndrico, reto ou curvo, limbo 5-partido, iguais ou não. Estames 2, anteriores, inclusos, anterars divergentes, estaminódios 2, posteriores, reduzidos; ovário 2-carpelar, carpelos uniovulados, estilete terminal, estigma orbicular, capitado. Fruto esquizocarpo, incluso no cálice, separando-se na maturidade em dois mericarpos uniseminados. Sementes sem endosperma.

\subsection{Stachytarpheta glabra Cham., Linnea 7: 250. 1832.}

Arbustos 0,6-2 m alt., glabros, ramos tetragonais. Folhas opostas, decussadas, pecíolos ca. $1 \mathrm{~cm}$, lâminas discolores, cartáceas, elíptico-lanceoladas, 2-4,5 cm compr., 1-2,3 cm larg., ápice acuminado, margem crenado-serreada, base atenuada, face adaxial verde-escura, nítida, face abaxial verdeclara. Inflorescências terminais, laxas, 3-7 cm compr., 2-2,5 $\mathrm{cm}$ larg., ráquis foveolada; bráctea adpressa ao cálice, subcartácea, lanceolada, ciliada, 5-7 mm compr., caducas; cálice azul-arroxeado, tubuloso, comprimido, ca. 1,5 cm compr., ca. $3 \mathrm{~mm}$ larg.; corola infundibuliforme 2,5-3 cm compr., 4-lobada, base lilás até roxa, externamente glandulosa, internamente alva, lobos obtusos. Fruto oblongo, ca. $8 \mathrm{~mm}$ compr., ca. 2 mm larg., castanho. (Fig. 2. P-Q)

Campos et al. CFCR 13480 (SPF); Cordeiro et al. CFCR 11512 (SPF); Mello-Silva et al. CFCR 9636, CFCR 10852 (SPF); Oliveira et al. CFCR 13043 (SPF); Pirani et al. CFCR 12476 (SPF).

Minas Gerais e Bahia, em áreas de campos rupestres com uma disjunção nas restingas do Rio de Janeiro. Em GrãoMogol, é encontrada entre afloramentos quartzíticos e arenosos ou à margem de cursos d'água, com floração durante todo o ano.

4.2. Stachytarpheta martiana Schauer in DC., Prodr. 11: 568. 1851.

Arbustos, 1-1,8 m alt., ramificados, glabros, ramos divergentes, tetragonais. Folhas opostas, decussadas, patentes, coriáceas, subsésseis, oblongo-obovadas, 5-9 cm compr., 2-3 cm larg., ápice obtuso, breve-acuminado, margem inteira da base até a metade do limbo, grosseiramente denteada até o ápice, base atenuada, glabra em ambas as faces. Inflorescências terminais, espigas 5-18 cm compr., laxas, ráquis foveolada, crassa; brácteas oval-lanceoladas, ca. $5 \mathrm{~mm}$ compr., ápice acuminado, ciliada; cálice verde-arroxeado, ca. $1,5 \mathrm{~cm}$ compr., ca. $2 \mathrm{~mm}$ larg., subestrigoso, glabrescente na frutificação, plicado, ápice 5-dentado; corola infundibuliforme, ca. 2,3 cm compr., tubo roxo, lobos azuis, glandulosa externamente. Fruto ca. $9 \mathrm{~mm}$ compr., ca. $3 \mathrm{~mm}$ larg., castanho, oblongo-obovado, acuminado. (Fig. 2. N-O)

Chukr et al. CFCR 9625 (SFF); Cordeiro et al. CFCR 958(SPF); Harley et al. 25058 (F, K, SPF); Hensold et al. CFCR 3504 (SPF); Oliveira et al. CFCR 12969 (SPF); Zappi et al CFCR 9824 (SPF).

Restrita aos campos rupestres da Cadeia do Espinhaço de Minas Gerais. Em Grão-Mogol, ocorre entre vegetação rupícola, em afloramentos quartzíticos ou em solo arenoso-fino, nos cerrados e carrascos.

4.3. Stachytarpheta spathulata Moldenke, Phytologia 29(2): 76-77. 1974.

Arbustos, 0,3-1,6 m alt., muito ramificado, ramos curtos, hirsutos, internós $0,5-1 \mathrm{~cm}$. Folhas opostas decussadas, espatuladas $0,8-1(-1,5) \mathrm{cm}$ diâm., cartáceas, discolores, ápice obtuso, arredondado, margem crenada, base atenuada, face adaxial verde-escura, hirsuta, face abaxial verde-clara, densamente incano-tomentosa. Inflorescência terminal, espiga 1,5-6 cm compr., congesta; brácteas oval-lanceoladas, ca. 5 $\mathrm{mm}$ compr., face adaxial glabra, face abaxial hirsuta; cálice ca. $7 \mathrm{~mm}$ compr., densamente hirsuto-canescente externamente; corola infundibuliforme, atrocerúlea, ca. $2 \mathrm{~cm}$ com- 


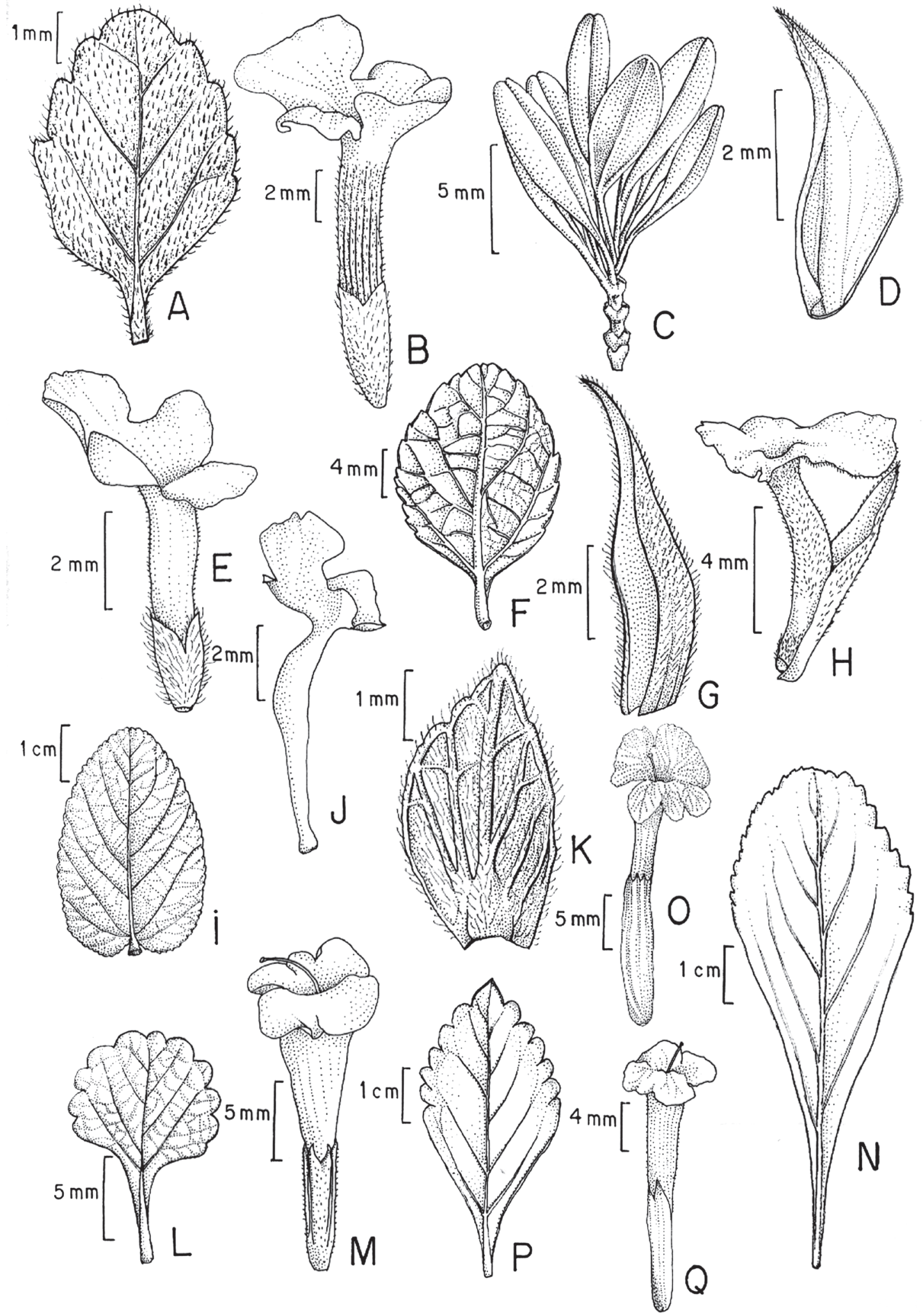

Fig. 2. VERBENACEAE. A-B. Lippia. hermannioides: A. Folha; B. Flor. C-E. L. thymoides: C. Braquiblasto com folhas; D. Bráctea; E. Flor. F-H. L. rotundifolia: F. Folha; G. Bráctea; H. Bráctea com flor. I-K. L. lacunosa: I. Folha; J. Flor; K. Bráctea. L-M. Stachytarpheta spathulata: L. Folha; M. Flor. N-O. S. martiana: N. Folha; O. Flor. P-Q. S. glabra: P. Folha; Q. Flor. 
pr., glabra externamente, tubo lilás, limbo azul, reduzido.

(Fig. 2. L-M)

Barreto et al. CFCR 11958 (SPF); Cordeiro et al. CFCR 937 (SPF); Esteves et al. CFCR 13319 (SPF); Furlan et al. CFCR 751 (SPF); Kawasaki et al. CFCR 8380 (SPF); Mamede et al. CFCR 3388 (SPF, holótipo de $S$. spathulata subsp. mogolensis S.Atkins; isótipo K); Mello-Silva et al. CFCR 9856 (SPF); Menezes et al. CFCR 9694 (SPF); Silva et al. (SPF).
Restrita aos afloramentos quartzíticos da Cadeia do Espinhaço, Minas Gerais, entre Diamantina e Montes Claros. Em Grão-Mogol, é muito freqüente, em áreas de brejos e ao longo de matas ciliares, com floração de outubro a março.

Atkins (2005) distinguiu aqui duas subespécies, sendo as populações da região de Grão-Mogol e Botumirim pertencentes a $S$. spathulata subsp. mogolensis S.Atkins.

\section{Vitex L.}

Árvore ou arbusto. Folhas opostas, decussadas, digitadas, 3-7-folioladas. Inflorescência em cimeiras, axilares ou terminais, reunidas em racemos terminais tirsóides. Flores monoclinas ou diclinas; cálice campanulado, ciatiforme ou cupuliforme, persistente no fruto, 5-partido; corola zigomorfa, tubulosa, bilabiada, limbo oblíquo, lábio anterior trilobado, o posterior bilobado; estames 4, didínamos, geralmente exserto; ovário 2-carpelar, 4-locular na antese, lóculos uniovulados; estilete com estigma bífido. Fruto drupa, pireno ósseo, 4-locular, lóculos unisseminados. Sementes obovadas ou oblongas, exalbuminadas.

\subsection{Vitex polygama Cham., Linnaea 7: 371. 1832.}

Árvores 2-6 m alt. Folhas 3-5-folioladas, pecíolos 6-12 cm compr., folíolos cartáceos a subcoriáceos, obovados ou oblongo-elípticos, o central 5-17 cm compr., 2-6 cm larg., os laterais 2,5-3,5 cm compr., ápice agudo, obtuso ou acuminado, face adaxial velutina, vinácea nos folíolos jovens, face abaxial densamente vilosa. Flores monoclinas zigomorfas, brácteas lanceoladas, cálice campanulado, tomentoso, per- sistente no fruto; corola lilás-azulada, tubo ca. $1,5 \mathrm{~cm}$ compr., fauce amarela, estames didínamos, anteras divergentes. (Fig. 1. D-E)

Assis et al. CFCR 11455 (CESJ, CTES, K, MBM, NY, SPF), 11542 (CESJ, F, SPF); Harley et al. 25134 (BHCB, CESJ, K, SPF).

Região sudeste e no Pará, Goiás e Mato Grosso, em capões e matas ciliares de toda. Em Grão-Mogol, ocorre em capões de mata montana e em capoeiras. 